\title{
MODELLING OF WORK OF THE ROTOR-TYPE BLADE PUMP WITH REVOLVING STATOR
}

\author{
V.T. DMYTRIV*, O.S. LANETS and I.V. DMYTRIV \\ Lviv Polytechnic National University, Institute of Mechanical Engineering and Transport \\ 1 Profesorska St., Lviv, 79013, UKRAINE \\ E-mail: Dmytriv_V@lukr.net \\ I.M. HORODETSKYY \\ Lviv National Agrarian University, Faculty of Mechanic and Power Engineering \\ Lviv-Dubliany, 80381, UKRAINE
}

\begin{abstract}
In the article, the analytical dependences of modelling the cell cross-sectional area between two adjacent blades of a rotary blade pump and capacity for a pump with fixed and rotating stators are given, and analytical dependences are derived to model the power necessary to overcome the friction forces of the blades. The forces acting on the radially placed blade of a rotary pump with a fixed stator (non-rotating or stationary) and a rotating stator are analyzed. Design and technological parameters that influence the pump capacity and power are taken into account. The power required for the movement of the pump blade without taking into account the compression of the air has the opposite character of the change as to the pump capacity The capacity of a rotary pump with a rotating stator is three times higher than that of a stationary stator. The rotary pump with a rotating stator, with six radially spaced blades, consumes $0.854[\mathrm{~kW}]$ less power to overcome the blade friction of $1.313[\mathrm{~kW}]$. The results of modelling of the pump work are given.
\end{abstract}

Key words: rotor-type pump, stator, capacity, analytical model, speed, acceleration.

\section{Introduction}

The question of the design of rotary pumps is relevant. According to JARN 2017, the annual production of positive displacement rotary compressors and pumps alone exceeds 154.3 million pieces and grows by $11.2 \%$ annually [1]. Designs of rotary pumps are improved without changing the process of their work.

Monasry et al. [2] calculated the basic design parameters and technological characteristics for a rotary pump without blades. They simulated the parameters and analyzed the power consumption of the drive. Lim et al. [3] determined the change in temperature, gas flow rate and mass flow rate through the end gaps of the rotor based on the simulation of gas flow in a rotary compressor using Mach number. The models were not tested experimentally.

Soedel [4] investigated a rotary roller compressor-pump with forced rotation. Tramschek and Ooi [5] examined the capacity of a rotary blade pump depending on the design of the intake and exhaust windows. Ma et al. [6] and Dmytriv et al. [7] believe that the disadvantage of rotary pumps is the mechanical friction of the rotor-stator and the blade-stator, which takes up to $30 \%$ of the total power. Ma et al [6] claim that the friction power of the blade tip and the stator is $81.2 \%$ of the mechanical friction force in pumps. The most difficult issue in research, which constrains the widespread use of rotary blade pumps is the power loss due to friction of the stator-blade and the reliability of this pair. Dmytriv et al. [8] and Mindaugas [9] stated that the pressure in the pump is lost due to the flow of air between the blade and the stator, and the coefficient of air friction is changed at significant flow rates. Many researches have studied the friction power loss and friction pair

\footnotetext{
${ }^{*}$ To whom correspondence should be addressed
} 
reliability, in particular Wu et al. [10], Kong et al. [11], Sarip et al. [12], Kawamura et al. [13], Hu et al. [14]. Costanzo et al. [15] simulated the pressure and temperature of a rotary blade pump using the compression ratio. The compression ratio was determined by the ratio of the measured inlet and outlet values of pressures or gas flow rates. Dmytriv et al. [7] proposed the flow rate or pump capacity coefficient (aspect ratio) taking into account the geometric dimensions of the rotary blade vacuum pump. The analytical dependence of the pump delivery rate takes into consideration the dynamic parameters of the pump, in particular the speed, pressure change of pump operation or power consumption.

In the first approximation, the distribution of forces of the "blade-stator" pair of the rotary pump can be identified with the work of bearing. Walicka et al. [16] considered the influence of the effects of complete inertia in the support bearing. Walicka et al. $[17,18]$ analysed the multi-lobed tapered bearing and determined its parameters based on Galerkin's method with an analysis of the power characteristics of the bearing. However, in this case, the mass and inertial components of the pump blade are not taken into account.

A number of studies presented in scientific articles have attempted to determine the influence of the pump design on its technological characteristics. Mohammed et al. [19] used the ANSYS Fluent software and finite element simulation of the flow of the medium in the working chambers of the pump. Cheng et al. [20] used the CFD COMSOL to model the force of the main elements in different dynamic conditions and to monitor the flow of the medium in the pump. Kolasinski et al. [21] believe that the numerical method of pumps modelling provides the reproducibility of results.

Therefore, it is important at the stage of improvement and development of rotary blade pumps to know the analytical model of its operation, which Petrović proved in [22]. Development of the analytical equations for modelling the characteristics of rotary blade pumps, which describe the design and technological parameters, and experimental study of the modelling results are issues of importance.

\section{Mathematical model of operation of the rotary blade pump}

The rotor-type pump works on the principle of filling with air and emptying the cells formed with two adjacent blades. The cross section of the cell changes due to eccentricity, the displacement of the rotor axis relative to the stator axis of the pump, and the angle of rotation of the rotor.

\subsection{The model of cell cross-sectional area of the rotary blade pump}

Let us consider the scheme of a rotary blade pump (Fig.1.) and determine the change in cross-sectional area of the cell when rotating the rotor with the blade at $\varphi$ angle.

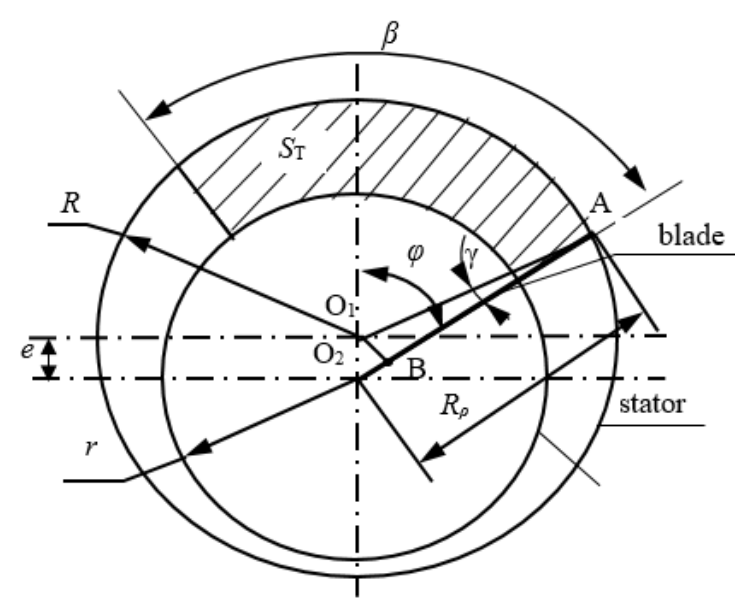

Fig.1. The scheme of cross-section of the rotor-type blade pump: $O_{1}-$ stator center; $O_{2}$ - rotor center. 
The area of the cell formed by the radial plates can be calculated by the formula:

$$
S_{T}=\frac{1}{2} \cdot \int_{\phi-0,5 \beta}^{\phi+0,5 \beta} R_{\rho}^{2} \cdot d \phi-\frac{1}{2} \cdot r^{2} \cdot \beta .
$$

From the scheme of the cross-section of the pump (Fig.1.) we can determine the radius vector:

$$
R_{\rho}(\phi)=e \cdot \cos \phi+R \cdot \cos \gamma
$$

where $e=R-r ; R=$ const.

To determine the angle $\gamma$ as a function of $\gamma=f(\varphi)$ let us draw the scheme from Fig.1. (Fig.2.).

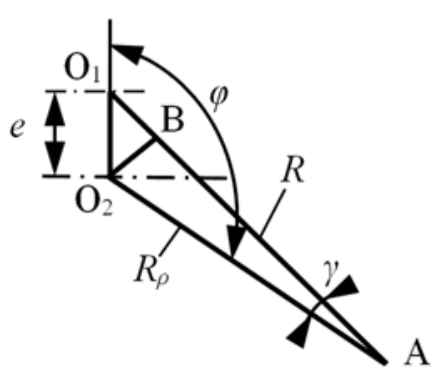

Fig.2. Scheme for determining the $\gamma$ angle between the $R$ body radius and $R_{\rho}$ radius-vector

To determine the angle $\gamma$ we can use the sine theorem (Fig.2.) $\frac{R}{\sin \phi}=\frac{e}{\sin \gamma}$, whence it follows:

$$
\gamma=\arcsin \left(\frac{e}{R} \cdot \sin \phi\right)
$$

Then Eq.(2.2) for the radius-vector we can write in the form of:

$$
R_{\rho}(\phi)=e \cdot \cos \phi+R \cdot \cos (\arcsin (\bar{\lambda} \cdot \sin \phi))
$$

where $\bar{\lambda}=e / R$.

We get the radius-vector formula after transformation in Eq.(2.4):

$$
R_{\rho}(\phi)=e \cdot \cos \phi+R \cdot \sqrt{1-\bar{\lambda}^{2} \cdot \sin ^{2}(\phi)}
$$

Taking into account Eq.(2.5), Eq.(2.1) will take the form of:

$$
S_{T}=\frac{1}{2} \cdot \int_{\phi-0,5 \beta}^{\phi+0,5 \beta}\left(e \cdot \cos \phi+R \cdot \sqrt{1-\bar{\lambda}^{2} \cdot \sin ^{2}(\phi)}\right)^{2} d \phi-\frac{1}{2} \cdot r^{2} \cdot \beta .
$$

We reduce Eq.(2.6) to a convenient form for integration: 


$$
\begin{aligned}
& S_{T}=\frac{1}{2} \cdot \int_{\phi-0,5 \beta}^{\phi+0,5 \beta}\left(e^{2} \cdot \cos ^{2} \phi-2 \cdot e \cdot \cos \phi \cdot R \cdot \sqrt{1-\bar{\lambda}^{2} \cdot \sin ^{2}(\phi)}+\right. \\
& \left.+R^{2}-e^{2} \cdot \sin ^{2}(\phi)\right) \cdot d \phi-\frac{1}{2} \cdot r^{2} \cdot \beta .
\end{aligned}
$$

The result of integrating of Eq.(2.7) is as follows:

$$
\begin{aligned}
& S_{T}=\frac{\beta}{2} \cdot\left(R^{2}-r^{2}\right)+\frac{e^{2}}{4} \cdot(\sin (2 \cdot \phi+\beta)-\sin (2 \cdot \phi-\beta))+ \\
& +e \cdot R \cdot \int_{\phi-0,5 \beta}^{\phi+0,5 \beta} \cos (\phi) \cdot \sqrt{1-\bar{\lambda}^{2} \cdot \sin ^{2}(\phi)} \cdot d \phi .
\end{aligned}
$$

Using the formula of trigonometric transformation, we will replace the second item in Eq.(2.8) and integrate the third item, the result will be as follows:

$$
\begin{aligned}
& S_{T}=\frac{\beta}{2} \cdot\left(R^{2}-r^{2}\right)+\frac{e^{2}}{2} \cdot \sin (\beta) \cdot \cos (2 \cdot \phi)+\frac{e \cdot R}{2} \cdot\left(\sin \left(\phi+\frac{\beta}{2}\right) \times\right. \\
& \times \sqrt{1-\bar{\lambda}^{2} \cdot \sin ^{2}\left(\phi+\frac{\beta}{2}\right)}-\sin \left(\phi-\frac{\beta}{2}\right) \cdot \sqrt{1-\bar{\lambda}^{2} \cdot \sin ^{2}\left(\phi-\frac{\beta}{2}\right)}+ \\
& \left.+\bar{\lambda} \cdot\left(\arcsin \left(\bar{\lambda} \cdot \sin \left(\phi+\frac{\beta}{2}\right)\right)-\arcsin \left(\bar{\lambda} \cdot \sin \left(\phi-\frac{\beta}{2}\right)\right)\right)\right)
\end{aligned}
$$

For the convenience of modelling, we write Eq.(2.9) using symbols:

$$
S_{T}=\frac{\beta}{2} \cdot\left(R^{2}-r^{2}\right)+\frac{e^{2}}{2} \cdot \sin (\beta) \cdot \cos (2 \cdot \phi)+\frac{e \cdot R}{2} \cdot\left(C_{1}+C_{2}\right)
$$

where $C_{1}, C_{2}$ are parts of integration:

$$
\begin{aligned}
& C_{1}=\sin \left(\phi+\frac{\beta}{2}\right) \cdot \sqrt{1-\bar{\lambda}^{2} \cdot \sin ^{2}\left(\phi+\frac{\beta}{2}\right)}-\sin \left(\phi-\frac{\beta}{2}\right) \cdot \sqrt{1-\bar{\lambda}^{2} \cdot \sin ^{2}\left(\phi-\frac{\beta}{2}\right)}, \\
& C_{2}=\bar{\lambda} \cdot\left(\arcsin \left(\bar{\lambda} \cdot \sin \left(\phi+\frac{\beta}{2}\right)\right)-\arcsin \left(\bar{\lambda} \cdot \sin \left(\phi-\frac{\beta}{2}\right)\right)\right) .
\end{aligned}
$$

The results of modelling of the change in the cross-sectional area of the rotary pump cell depending on the $\varphi$ angle of rotation of the rotor with a different number of blades are shown in Fig.5.

To model the capacity of the pump with a fixed stator and with the rotation of the stator, for vacuum, we use the existing dependences [7] and take into account the value of the pressure in the cell between two adjacent blades. The air is pumped out by a cell between two adjacent blades with a frequency corresponding to the rotor speed. The theoretical capacity of the pump without stator rotation when creating a vacuum, related to atmospheric pressure is calculated by the formula: 


$$
W_{T}=S_{T}^{\max } \cdot L_{p} \cdot Z_{л} \cdot \omega_{p} \cdot\left(\frac{S_{T}^{\min }}{S_{T}^{\max }}\right)^{n} \cdot\left(\frac{S_{T}^{\min }}{S_{T}^{\max }}\right)^{n} \cdot\left(S_{T}^{\max }\right)^{l-n} \cdot\left(S_{T}^{\min }\right)^{n-1}
$$

The theoretical capacity of the pump with rotating stator in vacuum mode, related to atmospheric pressure, taking into account the previous studies [7], is calculated as a function of:

$$
W_{T}=S_{T}^{\min } \cdot L_{p} \cdot Z_{л} \cdot \omega_{p} \cdot \frac{S_{T}^{\min }}{S_{T}^{\max }} .
$$

The results of modelling the capacity of a rotary pump with a fixed stator and with the rotation of the stator are shown on Fig.6.

To evaluate the energy efficiency of the pump, we will develop a mathematical model of the drive power of the rotary pump for the non-operating stroke without taking into account the air pumping.

\subsection{Analytical dependence of power consumption by the rotary pump}

\section{Rotary type-pump with fixed stator}

Let us consider the forces that are applied to the pump blade, which is placed radially (Fig.3.). The forces acting on the blade will be considered positive if they are directed from the center of the rotor.

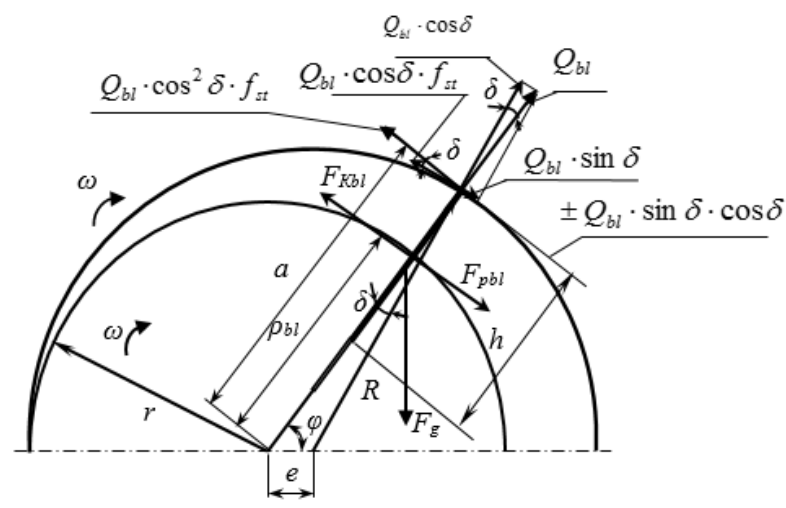

Fig.3. The scheme of forces acting on the radially placed blade of the pump.

Reduced to the centre of mass of the blade, the resultant of all forces acting along the blade and the stator, is calculated by the formula:

$$
Q_{b l}=F_{c}+F_{i b l} \pm F_{p b l} \cdot f_{2}-F_{g} \cdot \cos \phi
$$

where $F_{c}$ is the centrifugal force, which is positive at any point of the stator circle,

$$
F_{c}=m_{b l} \cdot \omega^{2} \cdot \rho_{b l}
$$

$F_{i b l}$ is the force of inertia of the blade, directed in the opposite to the acceleration,

$$
F_{i b l}=m_{b l} \cdot \frac{d^{2} \rho_{b l}}{d t^{2}}
$$


$F_{g}$ is the force of gravity of the blade directed downwards,

$$
F_{g}=m_{b l} \cdot g
$$

During the movement of the blade along the rotor slots, it is acted upon by the $F_{K b l}$ Coriolis force, which is calculated by the formula:

$$
F_{K b l}=2 \cdot m_{b l} \cdot \omega \cdot \frac{d \rho_{b l}}{d t} .
$$

Taking into account the above parameters, the mechanical power consumption for the friction of the blade is calculated analytically at different positions. To do this, we compose the equation of the moments of forces acting on the blade during its movement around the stator circle without taking into account the force of air compression:

$$
F_{p b l} \cdot \rho_{b l}=2 \cdot m_{b l} \cdot \omega \cdot\left|\frac{d \rho_{b l}}{d t}\right| \cdot \rho_{b l}+Q_{b l} \cdot \cos ^{2} \delta \cdot f_{s t} \cdot a \pm Q_{b l} \cdot \sin \delta \cdot \cos \delta \cdot a
$$

The resultant force of (2.13) acting on the blade is written taking into account Eqs (2.14)-(2.17):

$$
Q_{b l}=m_{b l} \cdot \omega^{2} \cdot \rho_{b l}+m_{b l} \cdot \frac{d^{2} \rho_{b l}}{d t^{2}} \pm F_{p b l} \cdot f_{2}-m_{b l} \cdot g \cdot \cos \phi_{1}
$$

Let us substitute the expression for $F_{p b l}$ of Eq.(2.18) into Eq.(2.19) and get:

$$
Q_{b l}=\frac{m_{b l} \cdot \omega^{2} \cdot \rho_{b l}+m_{b l} \cdot \frac{d^{2} \rho_{b l}}{d t^{2}} \pm 2 \cdot m_{b l} \cdot \omega\left|\frac{d \rho_{b l}}{d t}\right| \cdot f_{2}-m_{b l} \cdot g \cdot \cos \phi_{1}}{1-\frac{a}{\rho_{b l}} \cdot f_{2} \cdot\left(f_{s t} \cdot \cos \delta \pm \sin \delta \cdot \cos \delta\right)}
$$

The available value of $Q_{b l}$ in Eq.(2.20) is substituted into Eq.(2.18) and after the two parts are multiplied by $\Delta \varphi$ (in radians), we get the dependence to determine the elementary work done to overcome the friction of the blade against the stator, in the slots of the rotor and on the cover:

$$
\begin{aligned}
& \Delta L_{b l}^{i}=\left[2 \cdot m_{b l} \cdot \omega \cdot\left|\frac{d \rho_{b l}}{d t}\right| \cdot \rho_{b l}+\right. \\
& +\frac{m_{b l} \cdot \omega^{2} \cdot \rho_{b l}+m_{b l} \cdot \frac{d^{2} \rho_{b l}}{d t^{2}} \pm 2 \cdot m_{b l} \cdot \omega \cdot\left|\frac{d \rho_{b l}}{d t}\right| \cdot f_{2}-m_{b l} \cdot g \cdot \cos \phi_{1}}{1-\frac{a}{\rho_{b l}} \cdot f_{2} \cdot\left(f_{s t} \cdot \cos ^{2} \delta \pm \sin \delta \cdot \cos \delta\right)} \times \\
& \left.\times a \cdot\left(f_{s t} \cdot \cos ^{2} \delta \pm \sin \delta \cdot \cos \delta\right)\right] \cdot \Delta \phi .
\end{aligned}
$$




\section{Rotary-type pump with revolving stator}

In such a pump, the friction forces can be neglected provided that the linear speed of the blade at the point of contact with the stator is the same as the linear speed of the rotating stator at this point. The forces acting on the blade are different than in a pump with a fixed stator, they will be considered positive if they are directed from the center of the rotor (Fig.4.).

The $Q_{b l}$ resultant force of all forces acting along the blade and on the stator, the $F_{c}$ centrifugal force, which is positive at any point on the stator circle, the $F_{i b l}$ force of inertia of the blade, which is directed opposite to acceleration, and the $F_{K b l}$ Coriolis force created by the blade, the $F_{g}$ gravity force of the blade, which acts downward, are determined, respectively, by the dependences of (2.13)-(2.17).

The equation of mechanical power consumption is derived from the equation of moments of forces acting on the blade during its rotation together with the stator without taking into account the force of air compression:

$$
F_{p b l} \cdot \rho_{b l}=2 \cdot m_{b l} \cdot \omega \cdot\left|\frac{d \rho_{b l}}{d t}\right| \cdot \rho_{b l} \pm Q_{b l} \cdot \sin \delta \cdot \cos \delta \cdot a
$$

Let us substitute the expression for $F_{p b l}$ of Eq.(2.22) into Eq.(2.19) and get:

$$
Q_{b l}=\frac{m_{b l} \cdot \omega^{2} \cdot \rho_{b l}+m_{b l} \cdot \frac{d^{2} \rho_{b l}}{d t^{2}} \pm 2 \cdot m_{b l} \cdot \omega \cdot\left|\frac{d \rho_{b l}}{d t}\right| \cdot f_{2}-m_{b l} \cdot g \cdot \cos \phi_{1}}{1 \mp \frac{a}{\rho_{b l}} \cdot f_{2} \cdot \sin \delta \cdot \cos \delta} .
$$

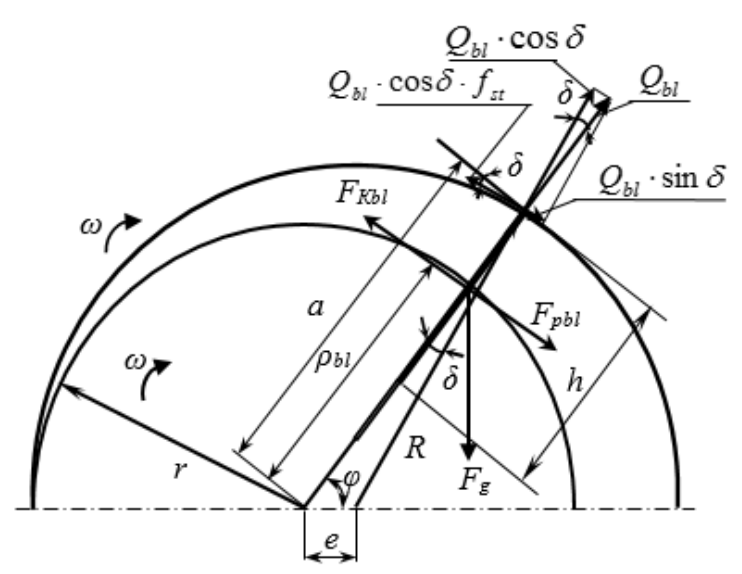

Fig.4. The scheme of forces acting on a the radially placed blade of the pump with a revolving stator.

The derived equation (2.23) for $Q_{b l}$ is substituted into Eq.(2.22) and, after both parts are multiplied by $\Delta \varphi$ (in radians), we get the dependence for determining the elementary work, which is done to overcome the friction forces of the blade in the slots of the rotor and on the covers: 


$$
\begin{aligned}
& \Delta L_{b l}^{i}=\left[\frac{m_{b l} \cdot \omega^{2} \cdot \rho_{b l}+m_{b l} \cdot \frac{d^{2} \rho_{b l}}{d t^{2}} \pm 2 \cdot m_{b l} \cdot \omega \cdot\left|\frac{d \rho_{b l}}{d t}\right| \cdot f_{2}-m_{b l} \cdot g \cdot \cos \phi_{1}}{1 \mp \frac{a}{\rho_{b l}} \cdot f_{2} \cdot \sin \delta \cdot \cos \delta} \times\right. \\
& \left.\times a \cdot \sin \delta \cdot \cos \delta+2 \cdot m_{b l} \cdot \omega \cdot\left|\frac{d \rho_{b l}}{d t}\right| \cdot \rho_{b l}\right] \cdot \Delta \phi .
\end{aligned}
$$

\section{Pump drive power without air compression}

The power $(k W)$ spent on the movement of the blade without air compression is calculated by the formula:

$$
W_{T}^{I}=\frac{Z_{b l} \cdot n_{r}}{60 \cdot 10^{3} \cdot \eta} \cdot \sum_{0}^{2 \pi} \Delta L_{b l}^{i}
$$

According to the schemes (Figs 1 and 2) we determine the values included in the analytical dependences of (2.21) and (2.24), which are functions of the $\varphi$ rotor angle. The $a$ distance is calculated by the formula:

$$
a=e \cdot \cos \phi+\sqrt{R^{2}-e^{2} \cdot \sin ^{2} \phi} .
$$

The distance from the centre of gravity of the rotor to the centre of gravity of the blade (radius-vector) is determined by the formula:

$$
\rho_{b l}=e \cdot \cos \phi+\sqrt{R^{2}-e^{2} \cdot \sin ^{2} \phi}-h / 2 .
$$

The speed of the blade:

$$
\frac{d \rho_{b l}}{d t}=e \cdot \omega \cdot \sin \phi \cdot \frac{\rho_{b l}+h / 2}{\rho_{b l}-e \cdot \cos \phi+h / 2}
$$

Acceleration of the blade:

$$
\begin{aligned}
& \frac{d^{2} \rho_{b l}}{d t^{2}}=\frac{e \cdot \omega}{\left(\rho_{b l}-e \cdot \cos \phi+h / 2\right)^{2}} \times\left[\operatorname { c o s } \phi \cdot \left(\rho_{b l} \cdot \omega \cdot h-\frac{d \rho_{b l}}{d t} \cdot e \cdot \sin \phi+\right.\right. \\
& \left.\left.+\omega \frac{h^{2}}{4}\right)-\rho_{b l} \cdot e \cdot \omega-e \cdot \omega \cdot h / 2\right] .
\end{aligned}
$$

\section{Results and discussions}

The cross-sectional area of the cell of the rotor blade pump (Fig.5) was modeled by the eccentricity of $e=0.01[\mathrm{~m}]$, the rotor radius of $r=0.06[\mathrm{~m}]$ and the internal stator radius of $R=0.07[\mathrm{~m}]$. 


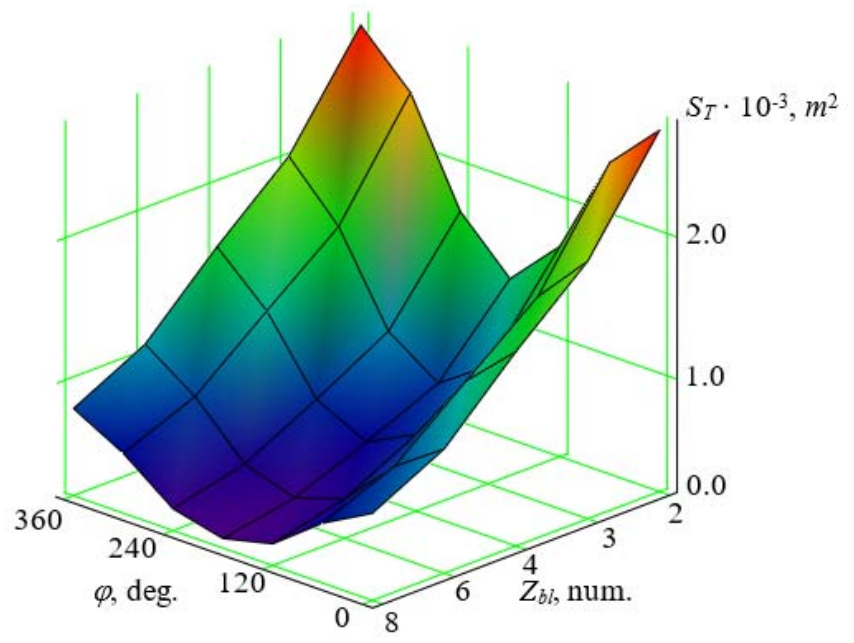

Fig.5. The functional dependence of the $S_{T}$ cross-sectional area of the cell between two adjacent blades of the rotor pump on the $Z_{b l}$ number of blades and the $\varphi$ angle of rotation of the rotor.

An analysis of the change in the cross-sectional area of the cell between two adjacent blades of the rotor type pump depending on the number of blades and the angle of rotation of the rotor showed that the cell area is maximum $S_{T}=0.002749\left[\mathrm{~m}^{2}\right]$ at $\varphi=0^{\circ}\left(360^{\circ}\right) 180^{\circ}$ and is minimal $S_{T}=0.001335\left[\mathrm{~m}^{2}\right]$ at $\varphi=180^{\circ}$ for a rotor with two blades. As the number of blades increases, the cross-sectional area of the cell between two adjacent blades decreases and is $S_{T}=0.0008188\left[\mathrm{~m}^{2}\right]$ at $\varphi=0^{\circ}\left(360^{\circ}\right)$ and $S_{T}=0.0002729$ at $\varphi=180^{\circ}$ for 8 blades (Fig.5.).

The results of capacity simulation for pumps without stator rotation and with stator rotation are shown in Fig.6. The speed was in the range of $930-1430\left[\mathrm{~min}^{-1}\right]$ and the number of plates (blades) was taken from 2 to 8 .

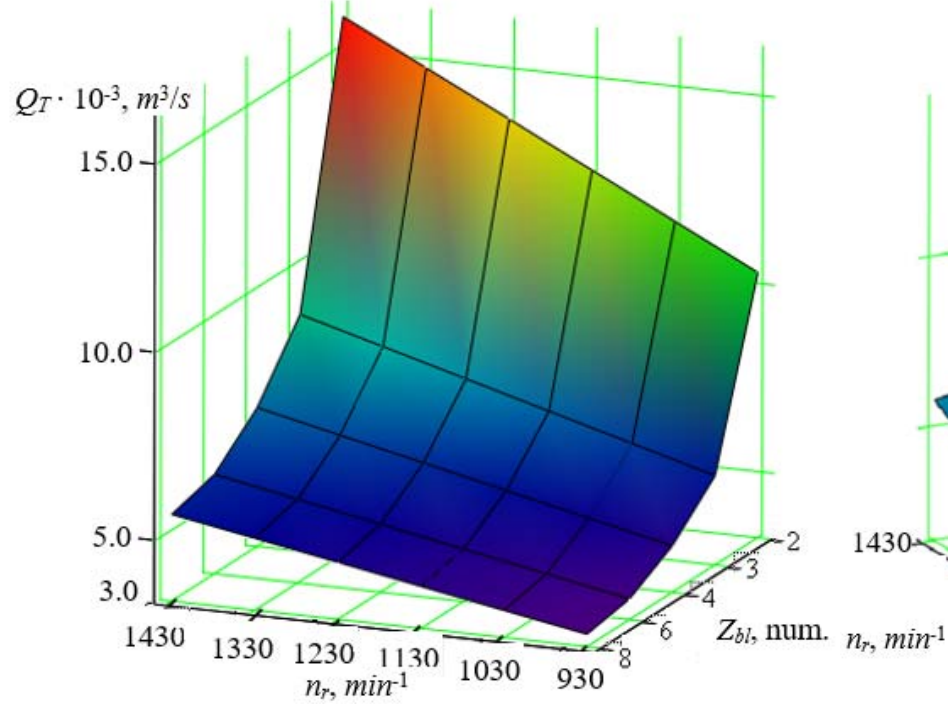

(a)

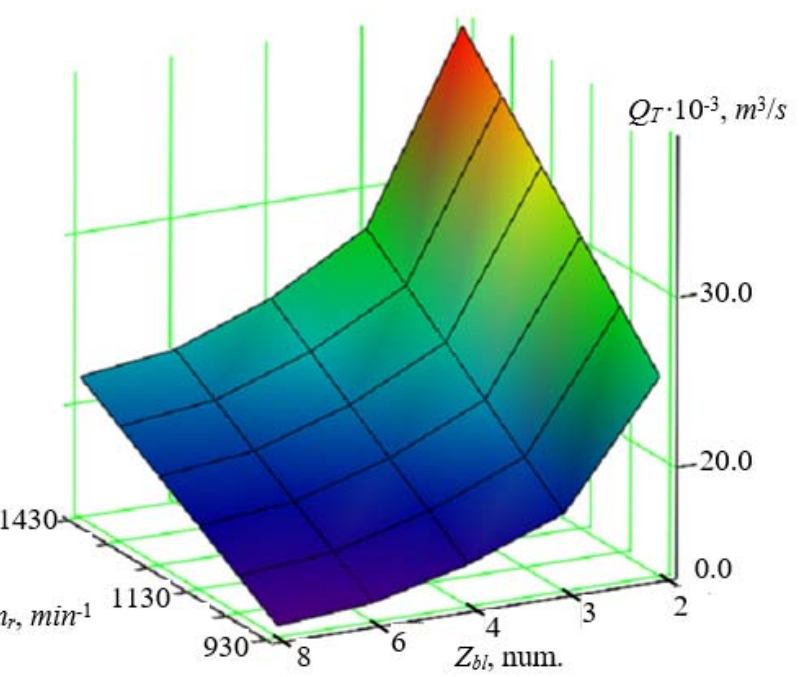

(b)

Fig.6. The results of modeling the $Q_{T}$ theoretical capacity of a rotary blade pump depending on the $Z_{b l}$ number of blades and the $n_{r}$ rotor speed for non-rotating stator (a) and with the rotating stator (b). 
The capacity of the pump at vacuum mode is increased with an increase of the rotor speed and with a decrease in the number of blades (Fig.6.).

For two blades, the capacity of a rotary pump with a rotating stator is 2.43 times higher compared to a pump with a non-rotating stator. As the number of blades increases, the difference in pump capacity increases as well. For eight blades, the capacity of a rotary pump with a rotating stator is 3.86 times higher than that without a rotating stator.

For modelling, the following parameters of the pump are accepted: eccentricity $e=0.01[\mathrm{~m}]$; rotor radius $r=0.06[\mathrm{~m}]$; the inner radius of the stator $R=0.07[\mathrm{~m}]$; angular rotor speed $\omega_{r}=149.67[\mathrm{rad} / \mathrm{s}]$; rotor length $L_{p}=0.2[\mathrm{~m}]$; blade height $h=0.032[\mathrm{~m}]$; blade mass, expressed by force $m_{b l}=0.064\left[N \cdot s^{2} / \mathrm{m}\right]$; blade friction coefficient $f_{2}=0.15$; the number of blades $Z_{b l}=6$; radial placement of the blades.

For a rotary blade pump with a non-rotating stator the power consumption to overcome the friction of the blades on the stator, in the slots of the rotor and on the covers is $2.167[\mathrm{~kW}]$.

The rotary pump with a rotating stator with 6 radially spaced blades, will consume power to overcome the friction of the blades by $0.854[\mathrm{~kW}]$ less, which is $1.313[\mathrm{~kW}]$.

\section{Conclusions}

The developed mathematical model allows modelling the elementary work which is done to overcome the friction of the blade to the stator, in slots of the rotor and inside covers. The analysis shows that a rotary blade pump with a rotating stator is more efficient than a pump with a non-rotating or fixed stator. The capacity of the rotary pump with the rotating stator is three times higher than that of the non-rotating stator. The power consumed by the friction of the blades is $0.854[\mathrm{~kW}]$ lower. The service life of the pump is higher. Such a pump is much more efficient.

\section{Nomenclature}

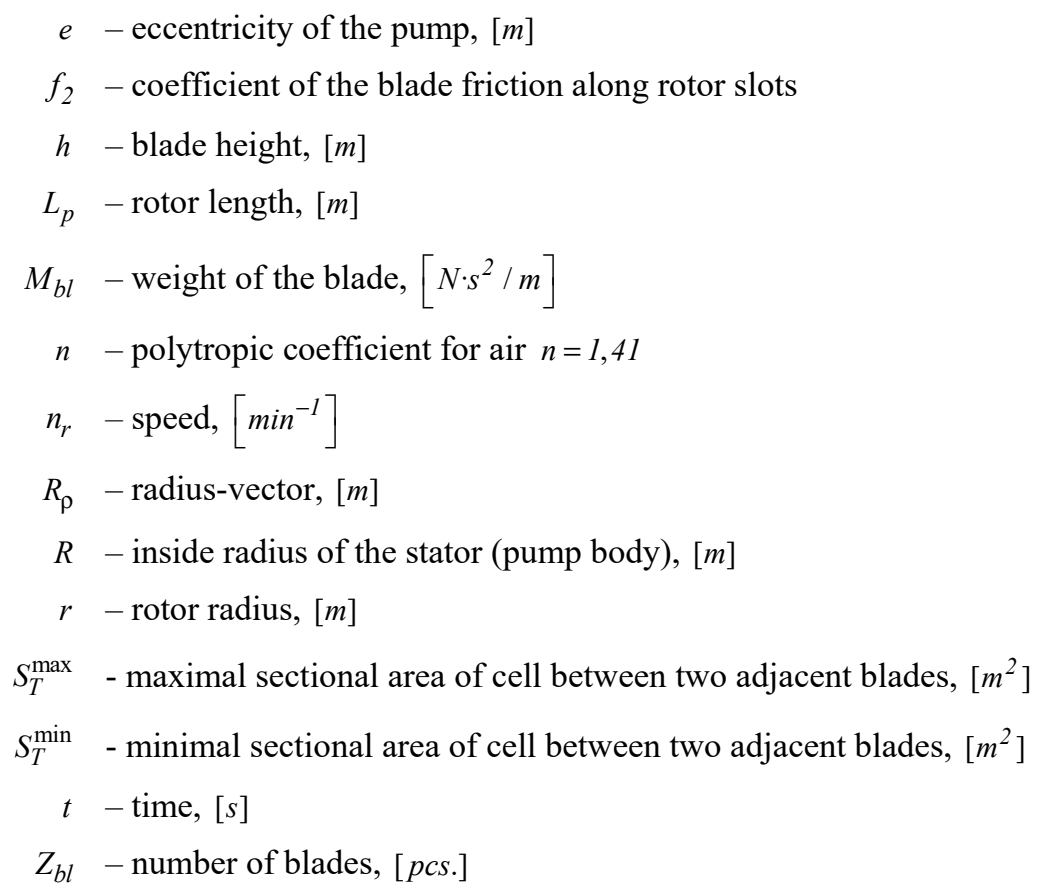


$\eta$ - coefficient that takes into account the friction of the blades on the pump cover and the friction in the bearings, we take $\eta=0$

$\beta$ - angle between two radial blades, $[\mathrm{rad}]$

$\varphi$ - angle of rotor rotation (blade), $[\mathrm{rad}]$

$\gamma$ - angle between the $R$ body radius and radius-vector $R_{\rho},[\mathrm{rad}]$

$\rho_{b l} \quad$ - spacing from rotor center to gravity center of the blade, $[\mathrm{m}]$

$\omega-$ angular velocity of the rotor, $[\mathrm{rad} / \mathrm{s}]$

$\omega_{r} \quad$ rotor speed, $[\mathrm{rad} / \mathrm{s}]$

\section{References}

[1] World Compressor Market (2017): Japanese Air Conditioning Heating and Refrigeration News.- March 25, pp.61-112.

[2] Monasry J.F., Aoki T., Shida S., Hatayama M., Hirayama T. and Okada M. (2018): Development of large capacity and high efficiency rotary compressor.- 24th International Compressor Engineering Conference at Purdue, July 912, paper 2576. [online]. Available at. https://docs.lib.purdue.edu/icec/2576

[3] Lim Yeu De, Poh Wai Chang and Ooi Kim Tiow. (2018): Leakage simulation of a lubricant-free rotary type swing compressor rotor endface clearance.- International Compressor Engineering Conference, paper 2612. [online]. Available at. https://docs.lib.purdue.edu/icec/2612

[4] Soedel W. (2006): Sound and Vibrations of Positive Displacement Compressors.- CRC press, p.343.

[5] Tramschek A. B. and Ooi, K. (1992): Effects of port geometry, dimensions and position on the performance of a rotary compressor.- Paper presented at the International Compressor Engineering Conference, paper 912. [online]. Available at. http://docs.lib.purdue.edu/icec/912

[6] Ma G.Y. and Li H.Q. (2001): Vane Compressor. Rotary Compressor (in Chinese).- BeiJing: China Machine Press, pp.92-183.

[7] Dmytriv V.T., Dmytriv I.V., Borovets V.M., Horodetskyy I.M., Kachmar R.Y. and Dmyterko P.R. (2019): Analyticalexperimental studies of delivery rate and volumetric efficiency of rotor-type vacuum pumps for milking machine.INMATEH - Agricultural Engineering, vol.58, No.2, pp.57-62. DOI: 10.35633/INMATEH-58-06

[8] Dmytriv V., Dmytriv I., Horodetskyy I. and Dmytriv T. (2019): Analytical dynamic model of coefficient of friction of air pipeline under pressure. - Diagnostyka, vol.20, No.4, pp.89-94. DOI: 10.29354/diag/114334

[9] Mindaugas R. (2017): Vane friction and wear influence on rotary vane compressor efficiency and operation: research and analysis review.- Agricultural Engineering, Research Papers, Vol.49, pp.1-12.

[10] Wu J., Zhang L., Huang L. and Tang Y. (2004): Numerical simulation and performance analysis of rotary vane compressors for automotive air conditioner.- International Compressor Engineering Conference at Purdue, paper 124. [online]. Available at. https://docs.lib.purdue.edu/icec

[11] Kong X.Z., Yang H.L. and Sun T.S. (2005): Study on the calculating model of power of vane compressor.- Fluid Machinery, vol.33, No.1, pp.25-27.

[12] Sarip A.R. and Musa M.N. (2012): Theoretical study of a novel multi vane rotary compressor.- International Compressor Engineering Conference at Purdue, paper 1307. [online]. Available at. https://docs.lib.purdue.edu/icec/2094

[13] Kawamura R., Sekiya S., Sasaki T., Maeyama H., Takahashi S. and Sugiura K. (2016): A study on high efficiency wing-vane compressor, part 1: a simulation analysis of dynamic model.- 23 International Compressor Engineering Conference at Purdue, July 11-14, paper 1104. [online]. Available at. https://docs.lib.purdue.edu/icec/2408

[14] Hu Y., Xu J., Wan P., Luo F., Wu F. and Ren L. (2018): A Study on novel high efficiency vane compressor.- 24 International Compressor Engineering Conference, July 9-12, paper 2601. [online]. Available at. https://docs.lib.purdue.edu/icec/2601

[15] Costanzo I., Valenti G., Murgia S. and Baia F. (2018): Experimental investigation on a novel two-stage sliding-vane air compressor based on the intracooling concept.- 24 International Compressor Engineering Conference, July 912, paper 2597. [online]. Available at. https://docs.lib.purdue.edu/icec/2597 
[16] Walicka A.and Jurczak P. (2017): Influence of total inertia effects in a thrust curvilinear bearing lubricated with newtonian lubricants.- Int. J. of Applied Mechanics and Engineering, vol.22, No.4, pp.1045-1058. DOI: 10.1515/ijame-2017-0067.

[17] Walicka A., Walicki E. and Jurczak P. (2019): Inertia effects in a multilobe conical bearing lubricated with a couple stress fluid.- Int. J. of Applied Mechanics and Engineering, vol.24, No.2, pp.439-451. DOI: 10.2478/ijame-2019-0027

[18] Walicka A., Jurczak P. and Falicki J. (2017): Curvilinear squeeze film bearing lubricated with a DeHaven fluid or with similar fluids.- Int. J. of Applied Mechanics and Engineering, vol.22, No.3, pp.697-715. DOI: 10.1515/ijame2017-0044

[19] Mohammed A., Nabil M., Ahmed El-Baz and Ashraf H. (2018): Flow modelling and performance assessment of rotary sliding vane pump using computational fluid dynamics.- Journal of Al Azhar University Engineering Sector, vol.13, No.49, pp.1268-1288. DOI: 10.21608/AUEJ.2018.18942

[20] Cheng Y., Wang X., Chai H., Sun T., Shahzad H. and Rehman W. (2021): The theoretical performance analysis and numerical simulation of the cylindrical vane pump.- Arabian Journal for Science and Engineering, vol.46, pp.29472961. DOI.org/10.1007/s13369-020-05294-9

[21] Kolasinski P., Błasiak P. and Rak J. (2016): Experimental and numerical analyses on the rotary vane expander operating conditions in a micro organic rankine cycle system.- Energies, vol.9, No.8, p.606, DOI.org/10.3390/en9080606

[22] Petrović R. (2009): Mathematical modeling and experimental verification of operating parameters of vane pump with double effect.- Strojniški vestnik - Journal of Mechanical Engineering, vol.55, No.1, pp.26-32.

Received: July 9, 2021

Revised: October 7, 2021 